\title{
Reliability of Two Color Selection Devices in Matching and Measuring Tooth Color
}

\author{
Carmen Llena, Esther Lozano, Jose Amengual, Leopoldo Forner
}

\begin{abstract}
Objective: The objective of this study was to investigate the intra and interdevice reliability of two tooth color measurement devices: EasyShade (ES) and SpectroShade Micro (SSM).
\end{abstract}

Materials and methods: Tooth color was measured in six maxillary and mandibular. $L^{*}, a^{*}$ and $b^{*}$ values and shade matches to VITA Classical and Vitapan 3D-Master shade guide systems were determined for all teeth. $\Delta \mathrm{E}$ was assessed. Paired t-test and correlation coefficient (ICC) were used.

Results: Intradevices no significant differences ( $p>0.05)$ were found between $L^{*}, a^{\star}, b^{\star}$. Interdevice $L^{*}$ and $b^{\star}$ were significantly higher for ES $(p<0.05)$, while $a^{\star}$ was significantly higher for SSM $(p<0.05)$. $\Delta E$ showed no significant interdevice difference $(p>0.05)$. Intradevices ICC values were higher for ES but not significant $(p>0.05)$.

Discussion: The null hypotheses that they present no differences in their color measuring within devices or shade systems is accepted, but the results allow to reject the null hypotheses that they present no differences in their color measuring or shade systems between devices.

Conclusion: Both EasyShade (ES) and SpectroShade Micro (SSM) show excellent repeatability and so they can be used in office to evaluate tooth color or to assess color changes after treatment.

Clinical significance: Dental color can be diagnosed using dental spectrophotometers, allowing to detect in an objective way therapeutic dental color changes.

Keywords: Dental color, EasyShade, Matching tooth color, Shade guide, Spectrophotometer, SpectroShade Micro, Laboratory research.

How to cite this article: Llena C, Lozano E, Amengual J Forner L. Reliability of Two Color Selection Devices in Matching and Measuring Tooth Color. J Contemp Dent Pract 2011; 12(1):19-23.

Source of support: Nil

Conflict of interest: None declared

\section{INTRODUCTION}

Visual tooth shade selection is characterized by high intraexaminer ${ }^{1}$ and interexaminer variability, ${ }^{2-4}$ due to the numerous subjective factors that affect color selection. Electronic shade selection devices have the potential for more accurate and reliable selection of a tooth color, ${ }^{5}$ since they are not influenced by the significant parameters in visual selection, such as illumination and operator variability. ${ }^{6}$ Matching validity and variability seem to improve with the use of shade selection devices, and some investigators have suggested that these devices can be useful in determining color quality for clinical shade matching. ${ }^{1,5,7}$

The most common devices are colorimeters and spectrophotometers, which calculate tooth color by measuring the amount and spectral composition of reflected light on the surface of the tooth. They usually express results based on the CIE $\mathrm{L}^{*} \mathrm{a} * \mathrm{~b}^{*}$ system ${ }^{8}$ as well as following one or more of the conventional shade guide systems.

CIE L*a*b* is one of the standard color mokdels used to describe all visible colors, using three basic coordinates. The L-value represents lightness, $a^{*}$ is a measure of red $\left(+a^{*}\right)$ or green $\left(-a^{*}\right), b^{*}$ is a measure of yellow $\left(+b^{*}\right)$ or blue $\left(-\mathrm{b}^{*}\right)$. The color difference between the color coordinates is calculated as $\Delta \mathrm{E}$, according to the equation: $\Delta \mathrm{E}=\left[\left(\mathrm{L}_{1}^{*}-\mathrm{L}_{2}^{*}\right)^{2}+\left(\mathrm{a}_{1}^{*}-\mathrm{a}_{2}^{*}\right)^{2}+\left(\mathrm{b}_{1}^{*}-\mathrm{b}_{2}^{*}\right)^{2}\right]^{1 / 2}$. Values of $\Delta \mathrm{E}$ greater than 1 unit were visually detectable by $50 \%$ of human observers in controlled conditions ${ }^{9}$ and color differences between 2.0 and 3.7 were visually detectable under clinical conditions. ${ }^{10}$ Spectrophotometers estimate color by measuring the intensity of the reflected light in all visible wavelengths, while colorimeters measure the intensity of the reflected light filtered by red, green, and blue filters (simulating RGB absorbance). These differences in the way intraoral shade matching instruments interpret the reflected light may directly affect the measuring functions of the devices, and indirectly, their matching function, which is based on the extrapolation of color measurement values into more meaningful values for a clinician, such as the shade 
tabs of a guide system. This presents a source of variation in the reliability of electronic and visual matching. ${ }^{4,11}$

Two commercially available spectrophotometers which can be used for measuring as well for matching teeth color are the VITA EasyShade (VITA Zahnfabrik, Bad Säckingen, Germany), and SpectroShade Micro (Medical High Technologies-MHT, Arbizzano di Negrar, Italy). Easy Shade (ES) has a central unit with a LED light source and a screen, connected via fiberoptic cable to a handset with a terminal and sensor at one end; it provides information on tooth $\mathrm{L}^{*}, \mathrm{a}^{*}, \mathrm{~b}^{*}$ parameters and establishes tooth color on the Vita Classical and the Vita System 3D-Master guides scales of colors. SpectroShade Micro (SSM) has a spectrophotometer with a LED illumination system which emits a constant light with a day light similar spectrum, a digital camera, an information analysis system and a screen. The colors are carried along the special light path, divided in two optic guides that converge symmetrically the light to the area of interest. The image of the analyzed area, illuminated with the colored light, is then reflected onto a special black and white CCD sensor located at the end of the optic system. This CCD sensor reads the data in the visible range from $400 \mathrm{~nm}$ to $700 \mathrm{~nm}$. The internal computer analyzes over 2 million reference points every time an image is acquired, and it is also able to drive all the functionalities of the instrument. It enables tooth color to be obtained on the basis of the color parameters of different guides, including Vita Classical and Vita 3D-Master.

Both devices have the dual function of measuring color and comparing it with the most commonly used in-office guides. The measuring function indicates the exact position of a tooth color in the observer's standard color space. The matching function indicates the degree to which a tooth matches a standard shade in a shade guide system. An important consideration is the ability of these instruments to measure tooth color reliably and accurately. Reliability refers to the consistency of the devices in matching the same specimen. Accuracy refers to the ability of the device to provide a correct match for a given specimen. ${ }^{1}$

Possible inconsistencies between devices in measuring color parameters or matching teeth to shade systems have been indicated in several studies. ${ }^{12,13}$ Despite the use of positioning guides and other options for taking measurements always at the same point, color measurement errors are frequent. As the literature shows, often intradevice consistency is good or very good, but interdevice consistency is weaker. ${ }^{14}$

The evaluation of intra and interdevice reliability in tooth color measurement is important in clinical practice, as is the ability to translate reliably three-dimensional color values to the shade tabs in the most commonly used guides.
For these reasons, the two devices were studied to test the null hypotheses that they present no differences in their color measuring within and between devices, as determined by the color parameters or shade systems.

\section{MATERIALS AND METHODS}

Tooth color was measured six maxillary and mandibular anterior teeth, caries and filling-free, in 10 young adults, four males and six females. Total tooth measured was 60 .

The participants were informed of the clinical procedure to which they would be subjected and they all agreed to take part in the study by signing an informed consent form. Research has been conducted in full accordance with ethical principles, including the World Medical Association Declaration of Helsinki.

The spectrophotometers used were EasyShade (ES) and SpectroShade Micro (SSM). Color data was exported into the CIE L*a*b* system for the color measuring process, and into the VITA Classical (VC) (VITA Zahnfabrik, Bad Säckingen, Germany) and Vitapan 3D-Master (3D) (VITA Zahnfabrik, Bad Säckingen, Germany) shade guide systems for the color matching process. The devices express tooth shades in a shade guide system, using conversion scales for CIE $\mathrm{L}^{*} \mathrm{a} * \mathrm{~b} *$ values, based on internally stored data. This function is performed automatically in every measurement with both devices.

To measure color with ES, a positioning tray was used in order to take the records always in the same place (middle third of the bucal aspect of the tooth). SSM was positioned and aligned correctly on the teeth using the positioning guide system which comes with the equipment.

All measurements were made by a single investigator experienced with both devices, following the manufacturer's instructions. Before any measurement, the devices were calibrated. The investigator was also calibrated by repeated tests on standard shade tabs taken from the two guides, until he repeatedly demonstrated less than $1 \Delta \mathrm{E}$ unit between measurements and an intraclass correlation coefficient (ICC) value greater than 0.85 .

The tooth was measured twice with each instrument with an interval of 1 hour, each CIEL *a*b* tooth measurement was the mean of 3 consecutive measurements.

The level of device differences in measuring tooth color was evaluated using paired t-tests on the $\mathrm{L}^{*} \mathrm{a} * \mathrm{~b} *$ and $\Delta \mathrm{E}$ values given by the devices. To estimate intra and interdevice reliability, ICC was used. The interpretation of ICC values was: Very good $(>0.90)$, good $(0.71-0.90)$, moderate $(0.51-0.70)$, mild $(0.31-0.50)$, null $(<0.31)$. To estimate the reliability of devices matching tooth color, Kappa indexes were calculated. For the VC guide, this was done in two stages. First, 16 colors were taken from the guide 
ordered by lightness and were assigned a number from 1 to 16 (Fig. 1) on a $2 \times 2$ Table. Agreements and disagreements were noted in the choice of color obtained with each of the devices independently and the Kappa index was calculated for each device in the two measurements (simple Kappa). The colors were then grouped in two categories, B1-D4 (lighter colors) and A3-C4 (darker colors), the interdevice Kappa index was calculated (grouped Kappa). For the 3D guide, the Kappa index was used to determine intra and interdevice consistency in luminosity. This was done by assigning a number to each group from 1 to 5 and noting the agreements and disagreements in a $2 \times 2$ Table. The interpretation of Kappa values was set as follows: Very good $(>0.80)$, good $(0.61-0.80)$, moderate $(0.41-0.60)$, mild $(0.21-0.40)$, very mild $(0-0.20)$. All tests were performed with a confidence interval of $95 \%$ using statistical software SPSS 15.0 (SPSS, Inc, Chicago, Ill).

\section{RESULTS}

Figure 2 shows that mean values in both explorations for $\mathrm{L}^{*}$ and $\mathrm{b}^{*}$ were higher with ES, while $\mathrm{a}^{*}$ was higher for SSM. The differences were not statistically significant in any case with the same device ( $p>0.05)$.

Comparing the mean values of color $\mathrm{L}^{*}, \mathrm{a}^{*}, \mathrm{~b}^{*}$ parameters measured by the two devices $\mathrm{L}^{*}$ and $\mathrm{b}^{*}$ values were significantly higher with $\mathrm{ES}$, and $\mathrm{a}^{*}$ were significantly higher with SSM, $\Delta \mathrm{E}$ were not significantly different between two devices (Table 1).

ICC showed good or very good consistency values for all parameters within devices (intradevice reliability), whereas between devices, values ranged between moderate and good (the results are shown in Table 2).

Agreement rates of devices in matching colors to conventional shade systems (VC and $3 \mathrm{D}$ ) are given in

\begin{tabular}{|l|c|c|c|c|c|c|c|c|c|c|c|c|c|c|c|c|}
\hline Vita shade guide & B1 & A1 & B2 & D2 & A2 & C1 & C2 & D4 & A3 & D3 & B3 & A3,5 & B4 & C3 & A4 & C4 \\
\hline Scores & 1 & 2 & 3 & 4 & 5 & 6 & 7 & 8 & 9 & 10 & 11 & 12 & 13 & 14 & 15 & 16 \\
\hline
\end{tabular}

Fig. 1: Vita classical guide shade colors organized by lightness (from the lightest -B1- to the darkest colors -C4-)
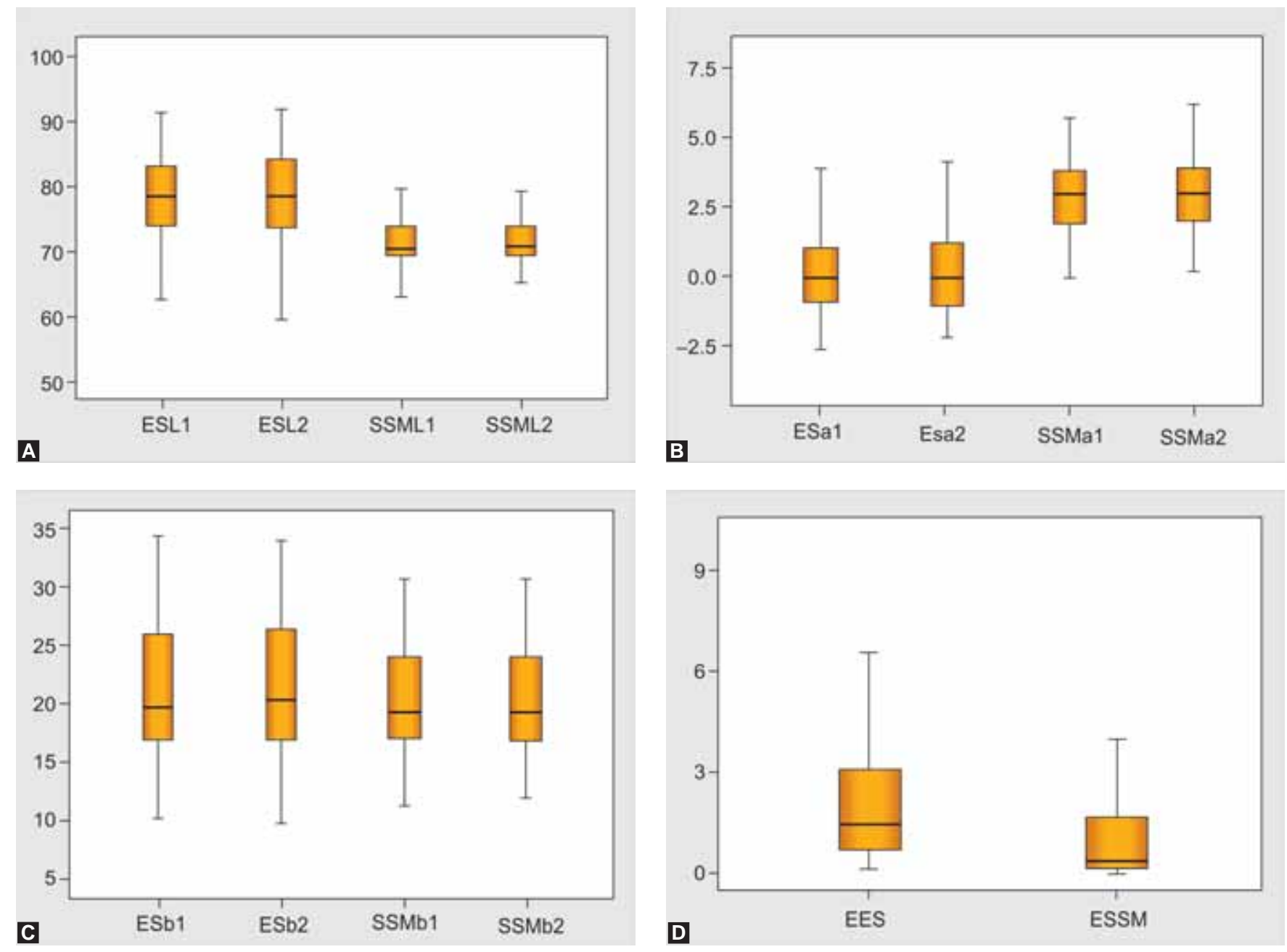

Fig. 2: Box-and-whisker plots of CIEL * $a^{*} b^{*}$ values with ES and SSM for the first and second measurements (A) $L^{*}$ values, (B) $a^{*}$ values, (C) $b^{*}$ values and (D) $\Delta$ E values 


\begin{tabular}{|c|c|c|c|c|c|c|c|c|c|c|c|c|}
\hline & & Mean & $S D$ & $p$-value & & Mean & $S D$ & $p$-value & & Mean & $S D$ & $p$-value \\
\hline$L^{*}$ values & $\begin{array}{l}\text { ES1 } \\
\text { ES2 }\end{array}$ & $\begin{array}{l}78.16 \\
78.45\end{array}$ & $\begin{array}{l}6.98 \\
7.19\end{array}$ & 0.80 & $\begin{array}{l}\text { SSM1 } \\
\text { SSM2 }\end{array}$ & $\begin{array}{l}71.58 \\
71.31\end{array}$ & $\begin{array}{l}4.40 \\
3.41\end{array}$ & 0.18 & $\begin{array}{l}\text { ES } \\
\text { SSM }\end{array}$ & $\begin{array}{l}78.45 \\
71.38\end{array}$ & $\begin{array}{l}7.07 \\
3.94\end{array}$ & $<0.001$ \\
\hline$a^{*}$ values & $\begin{array}{l}\text { ES1 } \\
\text { ES2 }\end{array}$ & $\begin{array}{l}0.21 \\
0.23\end{array}$ & $\begin{array}{l}1.69 \\
1.71\end{array}$ & 0.95 & $\begin{array}{l}\text { SSM1 } \\
\text { SSM2 }\end{array}$ & $\begin{array}{l}2.93 \\
2.97\end{array}$ & $\begin{array}{l}1.32 \\
1.45\end{array}$ & 0.81 & $\begin{array}{l}\text { ES } \\
\text { SSM }\end{array}$ & $\begin{array}{l}0.23 \\
2.92\end{array}$ & $\begin{array}{l}1.70 \\
1.38\end{array}$ & $<0.001$ \\
\hline$b^{*}$ values & $\begin{array}{l}\text { ES1 } \\
\text { ES2 }\end{array}$ & $\begin{array}{l}21.23 \\
21.17\end{array}$ & $\begin{array}{l}5.62 \\
5.76\end{array}$ & 0.80 & $\begin{array}{l}\text { SSM1 } \\
\text { SSM2 }\end{array}$ & $\begin{array}{l}20.24 \\
20.18\end{array}$ & $\begin{array}{l}4.02 \\
4.18\end{array}$ & 0.99 & $\begin{array}{l}\text { ES } \\
\text { SSM }\end{array}$ & $\begin{array}{l}21.26 \\
20.24\end{array}$ & $\begin{array}{l}5.68 \\
4.09\end{array}$ & 0.003 \\
\hline$\Delta \mathrm{E}$ & & & & & & & & & $\begin{array}{l}\text { ES } \\
\text { SSM }\end{array}$ & $\begin{array}{l}2.28 \\
1.69\end{array}$ & $\begin{array}{l}2.55 \\
4.32\end{array}$ & 0.184 \\
\hline
\end{tabular}

Mean, SD (standard deviation) and p-values of differences inter and intradevices in measuring CIEL*a* $\mathrm{b}^{*}$ color parameters. (ES: EasyShade SSM: SpectroShade Micro)

\begin{tabular}{cccc}
\multicolumn{4}{c}{ Table 2: Intraclass correlation coefficients } \\
\hline & \multicolumn{2}{c}{ ICC intradevice } & ICC interdevice \\
\cline { 2 - 3 } & ES & SSM & \\
\hline $\mathrm{L}^{*}$ & 0.955 & 0.815 & 0.657 \\
$\mathrm{a}^{*}$ & 0.971 & 0.890 & 0.798 \\
$\mathrm{~b}^{*}$ & 0.974 & 0.973 & 0.802 \\
\hline
\end{tabular}

Intraclass correlation coefficients (ICC) indicating intra and interdevice reliability in measuring tooth color, based on mean of two measurements

\begin{tabular}{|c|c|c|}
\hline & & Kарра \\
\hline \multirow[t]{3}{*}{ Vita classical } & SSM (Simple Kappa) & 0.990 \\
\hline & ES (Simple Kappa) & 0.963 \\
\hline & SSM/ES (Grouped Kappa) & 0.664 \\
\hline \multirow[t]{3}{*}{ Vita 3D Master } & SSM & 1 \\
\hline & ES & 0.977 \\
\hline & SSM/ES & 0.312 \\
\hline
\end{tabular}

Table 3, within devices reliability was very good for the two guides. Between devices for VC we obtained good consistency in the choice of light and dark colors (grouped Kappa), whereas in the choice of luminosity with the 3D guide, consistency was moderate.

\section{DISCUSSION}

The null hypotheses that they present no differences in their color measuring within devices or shade systems is accepted, but the results allow to reject the null hypotheses that they present no differences in their color measuring or shade systems between devices.

For both devices no differences were found between the mean values of the studied color parameters within devices. The color difference $(\Delta \mathrm{E})$ had average values of 2.28 and 1.69 units for the ES and SSM devices respectively. These values remains below the $50 \%$ acceptability level and perceptibility threshold for a clinical mismatch (5.5 and 2.6 $\Delta \mathrm{E}$ unities respectively). ${ }^{15}$ Since the investigator was well experienced with both devices, a significant part of these values may be attributed to tooth variance in surface morphology, convexity, and, primarily, enamel thickness and opacity, even though the teeth had been carefully selected. Minor variations in instrument repositioning could also have contributed to discrepancies in instrument consistency. Human tooth structure is difficult to measure consistently due to its polychromatic nature and its varying translucency and surface texture.

Between devices, ES provides significantly higher values of $\mathrm{L}^{*}$ (lightness) and $\mathrm{b}^{*}$ (chromaticity toward yellow), whereas SSM provides significantly higher values of a* (chromaticity toward red), nevertheless there are no significant interdevices differences between $\Delta \mathrm{E}$ mean values, being the means difference for $\Delta \mathrm{E}$ lower than 1 (not visually detectable by $50 \%$ of human observers in controlled conditions). ${ }^{9}$ Analysis of intradevice reliability shows very good values of ICCs for ES in all the parameters and between very good and good for SSM, with no intradevice differences. Measurement reliability for both devices is therefore very high so that either of these devices is able to repeat the same color parameters for a tooth several times, provided that it is measured in the same area, regardless of whether it is the true tooth color. Between devices, ICCs showed very good values for $\mathrm{a}^{*}$ and $\mathrm{b}^{*}$ and moderate for $\mathrm{L}^{*}$. Studies comparing reliability between different devices including SSM and ES show similar intradevice reliability for both devices and lower interdevice reliability values between these two devices. ${ }^{16}$

A study by Kim-Pusatery et al comparing the reliability of four devices (including both analyzed in our paper) do not find interdevice reliability differences between ES and SSM (96.4 and 96.9, respectively). ${ }^{17}$

The agreement obtained by simple Kappa with both devices for the VC guide was between the margins of "very good", however when the simple Kappa interdevices agreement was analyzed, very low values were obtained. When the 16 colors were grouped in the two categories, light and dark colors, interdevices agreement was "good", this data coincides with those reported by Meirles et al. ${ }^{18}$ With regard to the 3D Master guide, the intradevices 
agreement in matching teeth was very good for both devices, but the interdevices agreement was "mild”, lower agreement for the 3D system was also found by Lagouvardos et al. ${ }^{16}$ The lower agreement for the $3 \mathrm{D}$ guide may be due to the fact that it is newer than the VC guide and perhaps the algorithms for the devices studied need to be better fitted to the characteristics of this guide. Furthermore, this guide has 27 basic shade tabs in contrast to the 16 in the VC guide so there is more possibility of color matching variability, although in our study only agreement for the five possible levels of lightness was determined. It may be appropriate to take measurements with the shade tabs themselves to evaluate the accuracy and repeatability of the results shown by the devices and the real values, and even to establish if there is any difference between the capacity of devices when it comes to choosing some shade tab colors or others.

$\mathrm{New}$ in vitro studies with other spectrophotometric system $^{19}$ also show good reliability in assessing predictable repeated measurements.

\section{CONCLUSION}

Both in color matching with the guides and the threedimensional color evaluation, it is more appropriate to use the same device since comparison between the values obtained with different devices is difficult, however, with regard to intradevice reliability or agreement in matching tooth color within devices, both EasyShade (ES) and SpectroShade Micro (SSM), show excellent repeatability and so they can be used in office to evaluate tooth color or to assess color changes after treatment.

\section{CLINICAL SIGNIFICANCE}

Dental color can be diagnosed using dental spectrophotometers, allowing to detect in an objective way therapeutic dental color changes.

\section{REFERENCES}

1. Okubo SR, Kanawati A, Richards MW, Childress S. Evaluation of visual and instrument shade matching. J Prosthet Dent 1998;80:642-48.

2. Hammad IA. Intrarater repeatability of shade selections with two shade guides. J Prosthet Dent 2003;89:50-53.

3. Jarad FD, Russell MD, Moss BW. The use of digital imaging for colour matching and communication in restorative dentistry. Br Dent J 2005;199:43-49.

4. Klemetti E, Matela AM, Haag P, Kononen M. Shade selection performed by novice dental professionals and colorimeter. J Oral Rehabil 2006;33:31-35.

5. Paul S, Peter A, Pietrobon N, Hämmerle CH. Visual and spectrophotometric shade analysis of human teeth. J Dent Res 2002;81:578-82.

6. Dagg H, O’Connell B, Claffey N, Byrne D, Gorman C. The influence of some different factors on the accuracy of shade selection. J Oral Rehabil 2004;31:900-4.
7. Wee AG, Kang EY, Johnston WM, Seghi RR. Evaluating color match of different porcelain shade-matching systems. J Esthet Dent 2000;12:271-80.

8. CIE (Commission internationale de l'Eclairage). Colorimetrytechnical report. CIE Pub No 15 (3rd ed). Vienna: Bureau central de la CIE 2004.

9. Seghi RR, Hewlett ER, Kim J. Visual and instrumental colorimetric assessments of small color differences on translucent dental porcelain. J Dent Res 1989;68:1760-64.

10. Johnston WM, Kao EC. Assessment of appearance match by visual observation and clinical colorimetry. J Dent Res 1989;68: 819-22.

11. Hassel AJ, Koke U, Schmitter M, Rammelsberg P. Clinical effect of different shade guide systems on the tooth shades of ceramicveneered restorations. Int J Prosthodont 2005;18:422-26.

12. Dozić A, Kleverlaan CJ, El-Zohairy A, Feilzer AJ, Khashayar G. Performance of five commercial available tooth color-measuring devices. J Prosthodont 2007;16:93-100.

13. Hugo B, Witzel T, Klaiber B. Comparison of in vivo visual and computer-aided tooth shade determination. Clin Oral Investig 2005;9:244-50.

14. Douglas RD. Precision of in vivo colorimetric assessments of teeth. J Prosthet Dent 1997;77:464-70.

15. Douglas RD, Steinhauer TJ, Wee AG. Intraoral determination of the tolerance of dentists for perceptibility and acceptability of shade mismatch. J Prosthet Dent 2007;97:200-08.

16. Lagouvardos PE, Fougia AG, Diamantopoulou SA, et al. Repeatability and interdevice reliability of two portable color selection devices in matching and measuring tooth color. J Prosthet Dent 2009;10:40-45.

17. Kim-Pusateri S, Brewer JD, Davis EL, Wee AG. Reliability and accuracy of four dental shade-matching devices. J Prosthet Dent 2009;10:193-99.

18. Meireles SS, Demarco FF, dos Santos Ida S, Dumith Sde C, Bona AD. Validation and reliability of visual assessment with a shade guide for tooth-color classification. Oper dent 2008;33: 121-26.

19. Chen L, Tan JG, Zhou JF, Yang X, Du Y, Wang FP. Reliability and accuracy of crystal eye spectrophotometric system. Chin J Dent Res 2010;13:139-45.

\section{ABOUT THE AUTHORS}

\section{Carmen Llena}

Professor, Department of Stomatology, University of Valencia, Spain

\section{Esther Lozano}

Collaborator, Department of Stomatology, University of Valencia Spain

\section{Jose Amengual}

Associate Professor, Department of Stomatology, University of Valencia, Spain

\section{Leopoldo Forner}

Professor, Department of Stomatology, University of Valencia, Spain

\section{CORRESPONDING AUTHOR}

Carmen Llena, Clinica Odontológica, Universitat de València, C Gascó Oliag, 1, 46010 Valencia, España, e-mail: llena@uv.es 